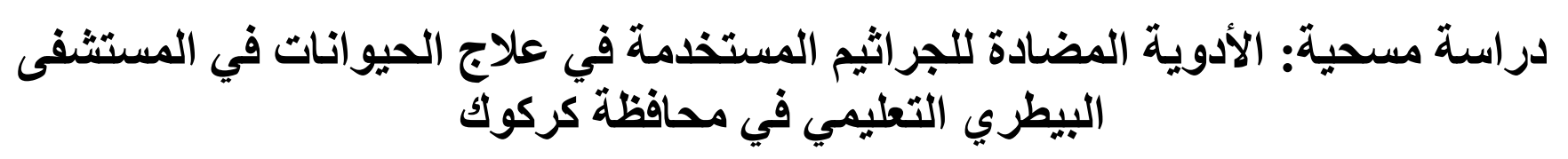

يعرب جعفر موسى *، عصام رائد محمد، سهند سامان رمضان و مصطفى محمد هادي

فرع الفسلجة و الكيمياء الحياتية والأدوية، كلية الطب البيطري، جامعة الموصل، الموصل، العراق

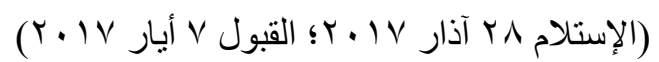

الخلاصة

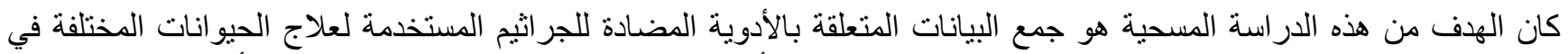

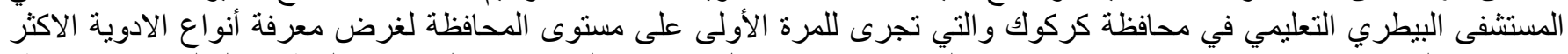

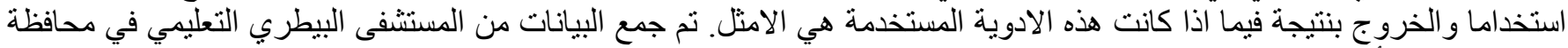

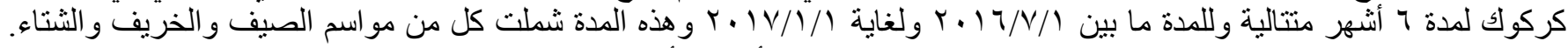

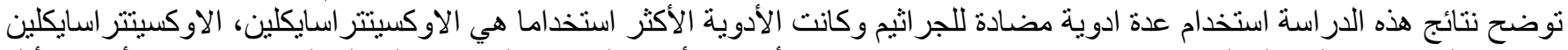

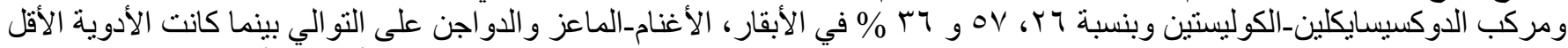

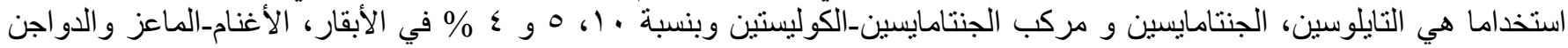

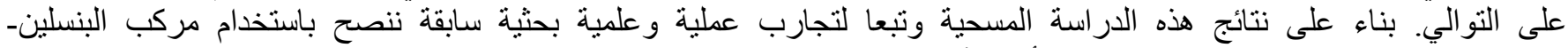

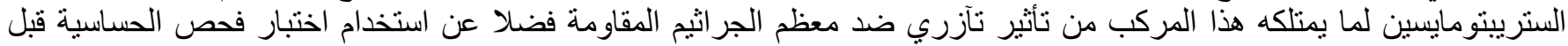

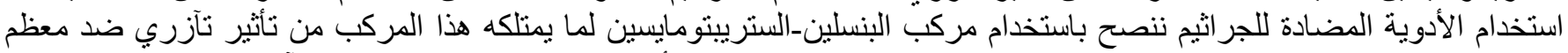

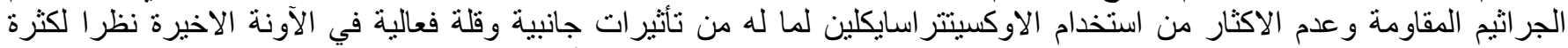

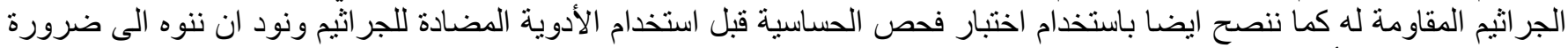

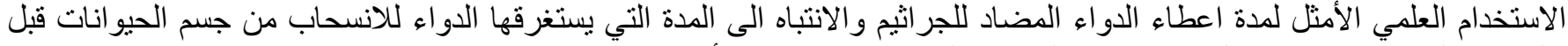
حلب هذه الحيو انتات او ذبحها لكي لا نتطور المقاومة الجئ الجرثومية ضد هذه الأدوية مستقبلا.

\title{
Survey study: The antibacterial drugs used for treatment of the animals in the teaching veterinary hospital in Kirkuk province
}

\section{Y.J. Mousa*, E.R. Mohammad, S.S. Ramadhan and M.M. Hadi}

Department of Physiology, Biochemistry and Pharmacology, College of Veterinary Medicine, University of Mosul, Mosul, E-

\author{
E-mail: yarub204@yahoo.com
}

\begin{abstract}
The aim of this survey is to collect data relating to antibacterial drugs used to treat different animals in the veterinary teaching hospital in the province of Kirkuk, which is taking place for the first time at the province level for the purpose of knowing the types of drugs most commonly used and the outcome whether these drugs used are optimal. Data were collected from the veterinary teaching hospital in Kirkuk province for 6 consecutive months and for the period between 1/7/2016 and until 1/1/2017 period included both the summer and autumn and winter seasons. The results show that the most commonly used drugs were Oxytetracycline, Oxytetracycline, Doxycycline-Colistin compound by 26, 57 and 36\% in cattle, sheep-goats and Poultry, respectively. While the least commonly used drugs were Tylosin, Gentamicin and Gentamicin-Tylosin compound by 10,5 and $4 \%$ in cattle, sheep-goats and poultry, respectively. Based on the results obtained from this survey, we recommend the use of Penicillin-Streptomycin compound because it has a synergistic effect against most of the resistant bacteria and not to increase usage of Oxytetracycline because of its side effects and lack of effectiveness in recent times due to
\end{abstract}


the abundance of resistant germs. Also, using antibacterial drugs, we would like to note the need for optimal scientific use of these drugs and to give attention to the period in which it takes the medicine to withdraw from the animal body before milking animals or slaughtering it, so that the bacterial resistance does not develop against these drugs in the future.

Available online at http://www.vetmedmosul.org/ijvs

استخدام دواء مضاد للجراثيم وخلال مدة زمنية شملت مدة التئ المقدمة

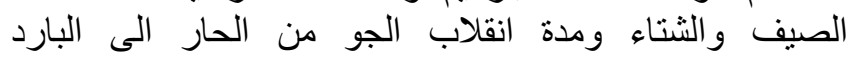

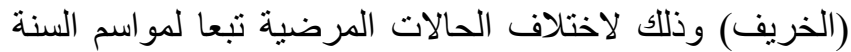

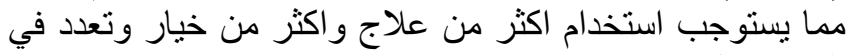
الحالات المرضية.

وتتاولت هذه الدراسة ايضا وضع حلول للاستخدام الخاطئ

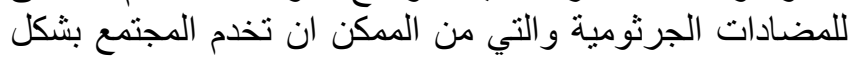

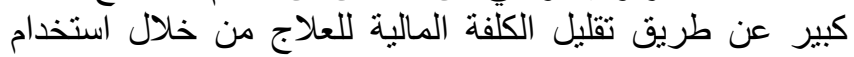

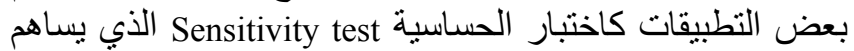
في الاختيار الدقيق للعلاج ويختصر طات طريقا طويلا على الطبي الطبيب

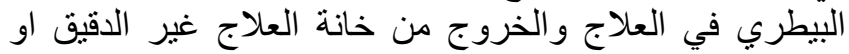

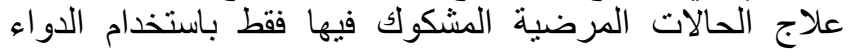

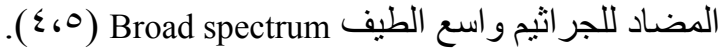

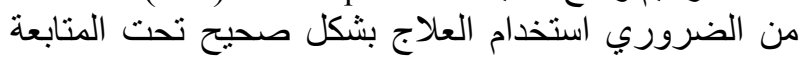

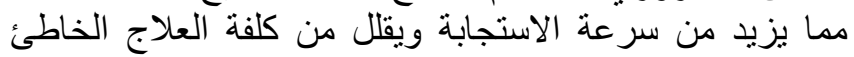

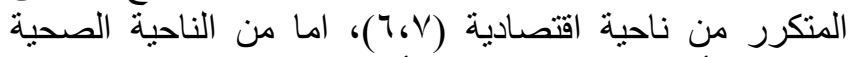

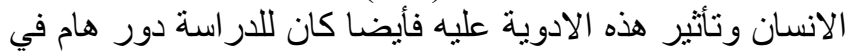

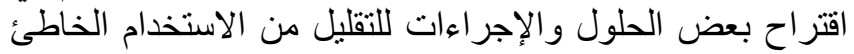

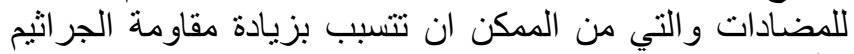

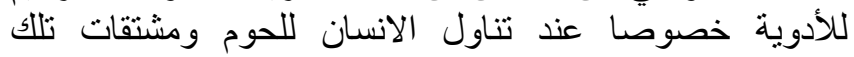

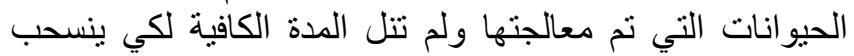

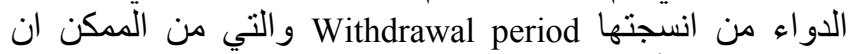

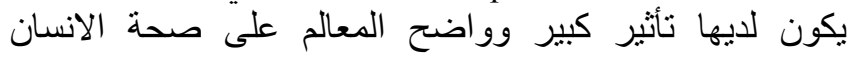

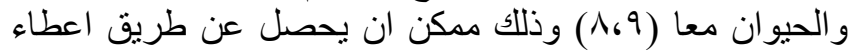

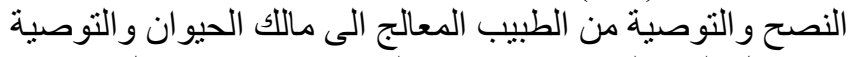

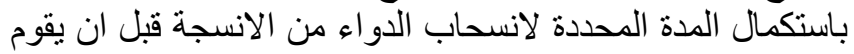

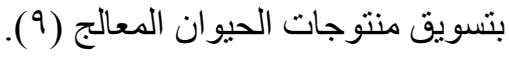

\section{المواد وطر ائق العمل}

اجريت هذه الدراسة المسحية عن طريق جمع البيانات من في البرئ

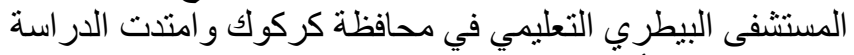

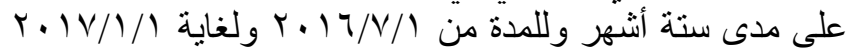

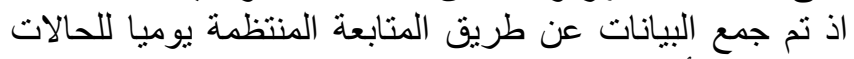
التي كانت تأتي للمستشفى البيطري والتئ التي كانت التئن تستدعي استخدام

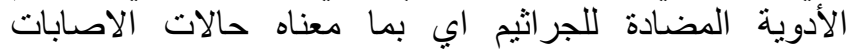

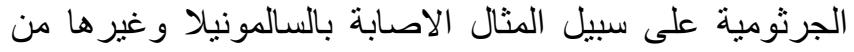

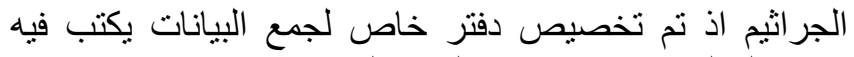
تاريخ الحالة ونوع الأمـابة والدو اء الذي تم صرفه.
تعد الادوية المضادة للجراثيم Antibacterial drugs من الإل

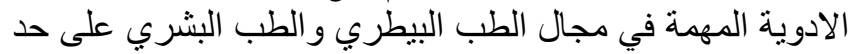

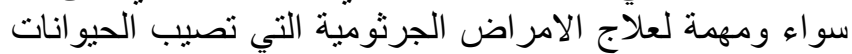
المختلفة اذ تعتبر من الأدوية عظيمة الأهمية إذاذ تمثية استعمالها

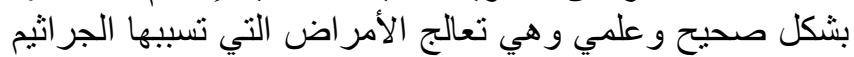

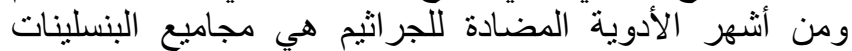
و التتر اسايكلينات Tenicillins

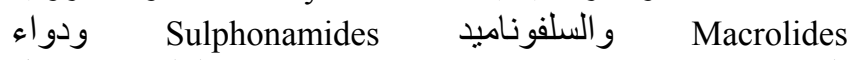

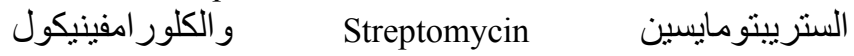

(1) Chloramphenicol وتعمل الأدوية المضادة للجر اثثم ضد أنواع مختلفة الجر اثثم

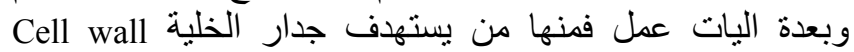

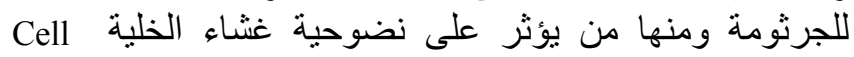
membrane Protein synthesis inhibitors الاحماض النووية الجرثومية او تؤثر على الجئ العمليات الأيضية

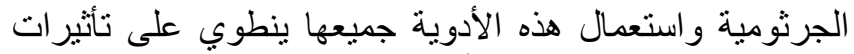

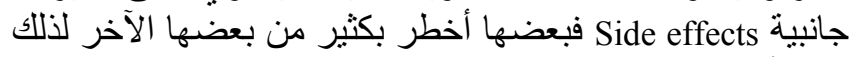

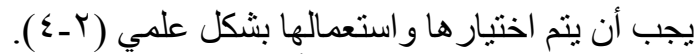

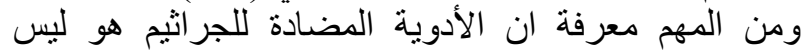

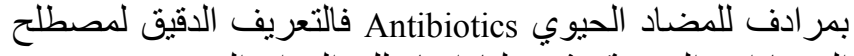

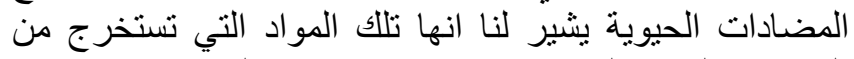

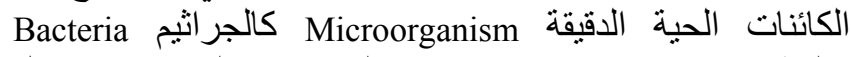
والفطريات Fungi وهذا يعني بان المضادات الحفة الحيوية لا تشمل

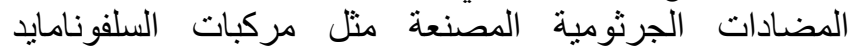
و الكينولونات Quinolones او المضادات الجرثية الجنومية شبه المصنعة Semisynthetic Amoxicillin

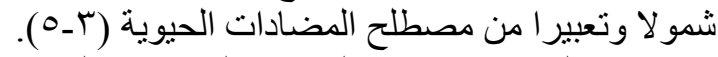

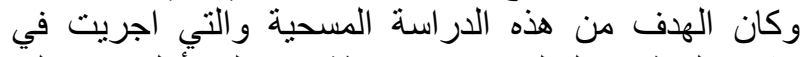

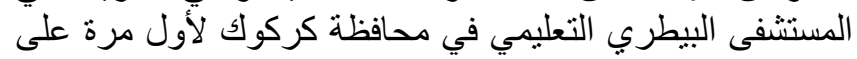

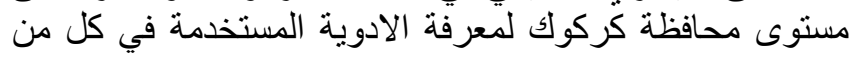

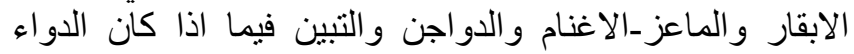

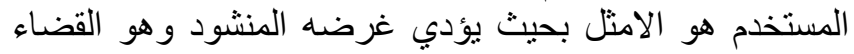

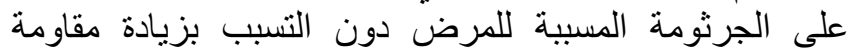

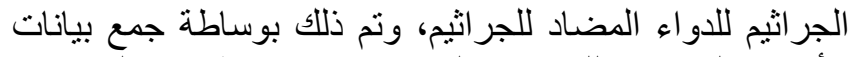

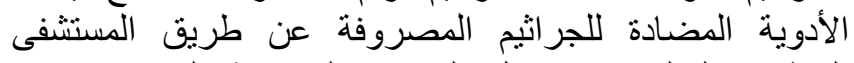
البيطري التعليمي وتسجيل الحالات المرضية التئي استوجبت المبنى 


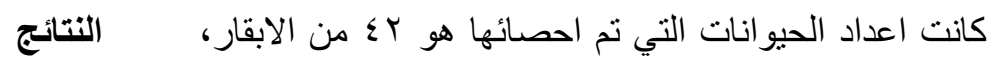

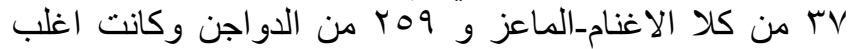

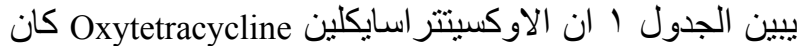

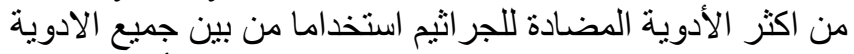

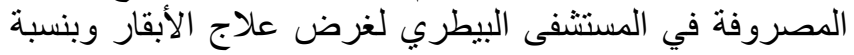

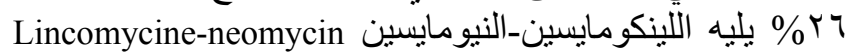

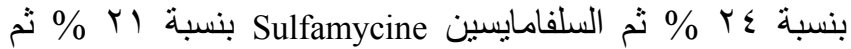
الاموكسيسلين Amoxicillin بنسبة 19 1 \% و وكان الدواء الاقل

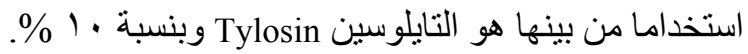

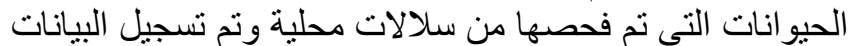

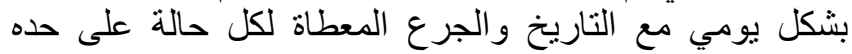

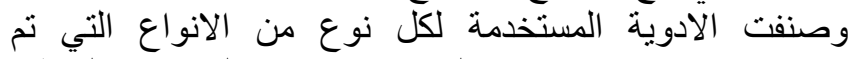

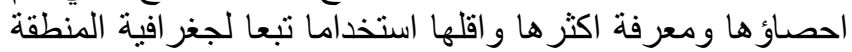

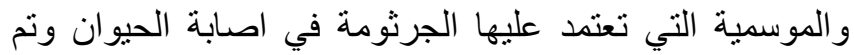

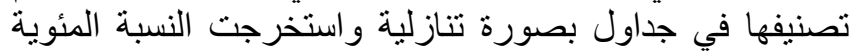
لاستخدام الدو اء المضاد للجر اثيم حسب المعادلة الرياضية التالية:

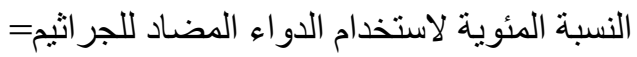

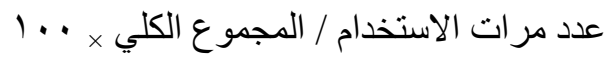

الجدول 1: الادوية المضادة للجر اثيم المستخدمة لعلاج الأبقار في المستشفى البيطري التعليمي في محافظة كركوك

\begin{tabular}{|c|c|c|}
\hline النسبة المئوية (\%) & عدد مرات الاستخدام & الدواء المضـاد للجر اثيم وتركيزه المستخدم \\
\hline rT & 11 & الاوكسيتتر اسايكلين (•r \%) \\
\hline$r \varepsilon$ & 1. & 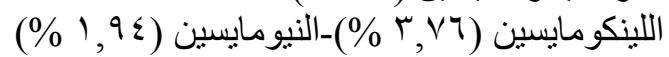 \\
\hline r) & 9 & 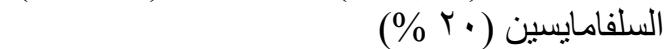 \\
\hline 19 & $\wedge$ & الأمو كسيسلين (10 \%) \\
\hline $1 \cdot$ & $\varepsilon$ & التايلوسين (•r \% \%) \\
\hline $1 \cdots$ & $\varepsilon r$ & المجموع الكلي \\
\hline
\end{tabular}

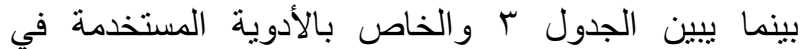

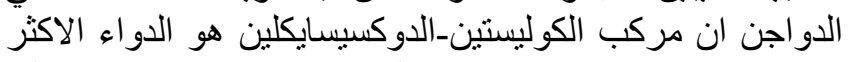

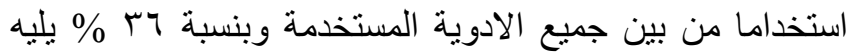

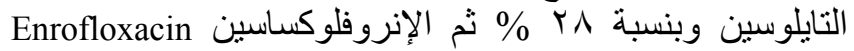

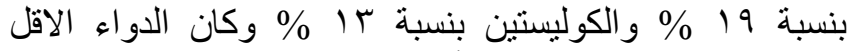

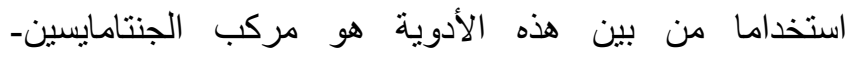

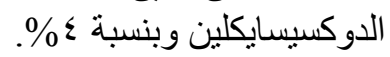

وكانت معظم طرق الاعطاء للأدوية سابقة الذكر هو هو الاعن عن طريق الحقن العضلي Intramuscular الضرع عالهول

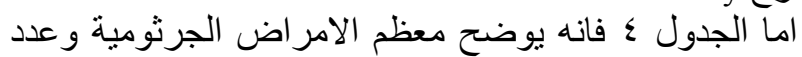

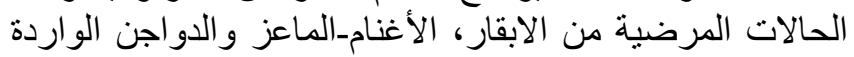

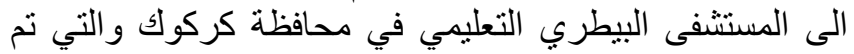
جمعها طول فترة الدر اسة.
ويوضح الجدول r ان الاوكسيتتراسايكلين كان من اكثر

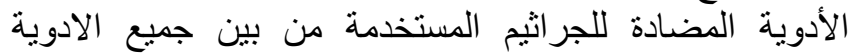

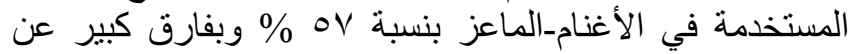

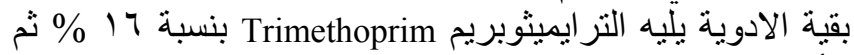

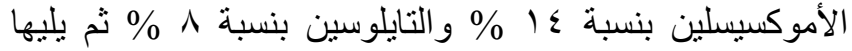

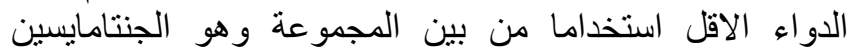

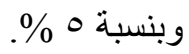

الجدول r ب: الادوية المضادة للجر اثيم المستخدمة لعلاج كل من المن فيطي الاغنام_الماعز في المستثفى البيطري التعليمي في محافظة كركوك الام

\begin{tabular}{|c|c|c|}
\hline النسبة المئوية & الاستخدام & ونركيزه الدواء المضاد للجر اثيم \\
\hline ov & YI & الاوكسيتتر اسايكلين (·ץ\%\%) \\
\hline 17 & 7 & التر ايميثوبريم (^ \%) \\
\hline $1 \varepsilon$ & 0 & الأموكسيسلين (10 \% \%) \\
\hline$\wedge$ & r & التايلوسين (•r \% \%) \\
\hline 0 & r & الجنتامايسين (· ( \%) \\
\hline $1 \ldots$ & re & المجموع الكلي \\
\hline
\end{tabular}


الجدول r: الادوية المضادة للجر اثيم المستخدمة لعلاج الدواجن في المستشفى البيطري التعليمي في محافظة كركوك

\begin{tabular}{|c|c|c|}
\hline النسبة المئوية (\%\%) & عدد مر ات الاستخدام & الدواء المضـاد للجر اثيم وتركيزه المستخدم \\
\hline$r q$ & $9 r$ & 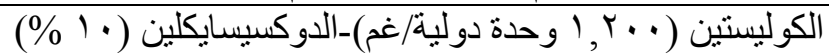 \\
\hline rᄉ & $\vee \leqslant$ & 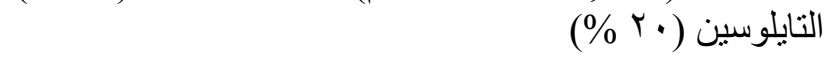 \\
\hline 19 & $\leqslant 9$ & الإنروفلو كساسين (•r \% \%) \\
\hline 1T & r & 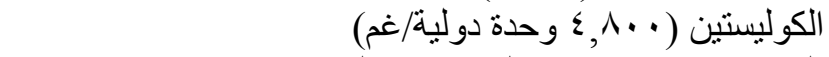 \\
\hline$\varepsilon$ & 11 & الجنتامايسين (•r\%\%)_الدوكسيسايكلين (•r\%\%) \\
\hline $1 \cdots$ & roq & المجموع الكلي الم \\
\hline
\end{tabular}

اذ يعتبر الاوكسيتتر اسايكلين مثبط لنمو الجر اثيم Bacteriostatic

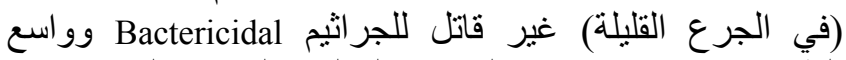

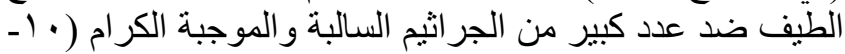
(1)

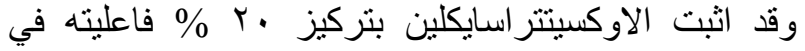

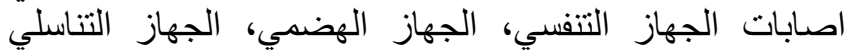

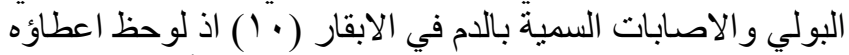

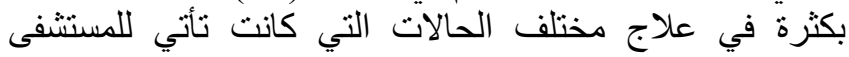
البيطري التعليمي ولكن هذا الاعطاء لا لإي يمكن ان يكون دقيقا بنسبة

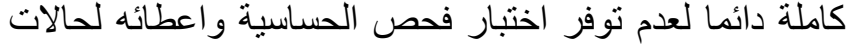

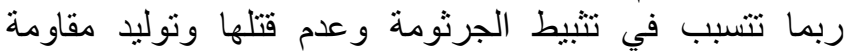

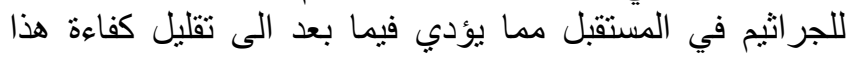

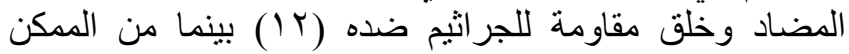

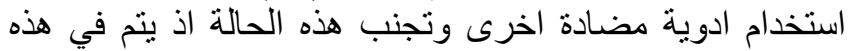

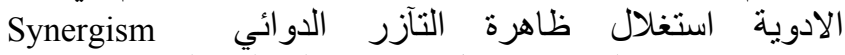
المعروفة مثل مركب البنسلين-الستربتومايسين (Potentiation)

وتم استخدام مركب اللينكومايسين-النيومايسين في حالات

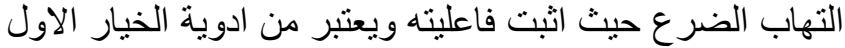
First choice

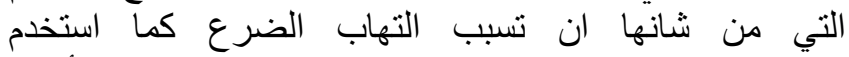

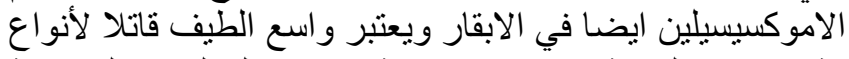

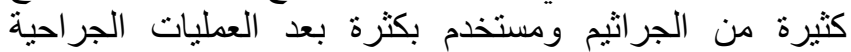
Postoperative للمرض ولكن كوقاية من الاصابات الثانوية المصاحبة لقلة التابة

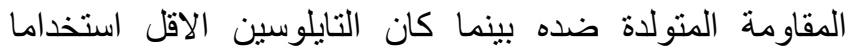

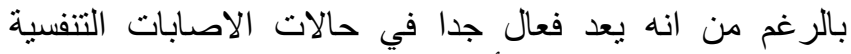

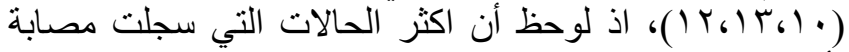

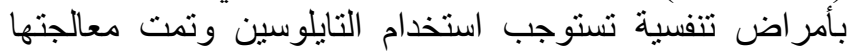
باستخدام الاوكسيتتر اسايكلين.

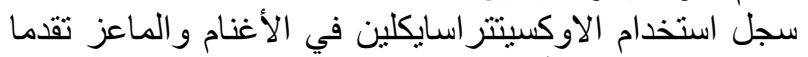

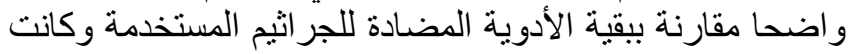

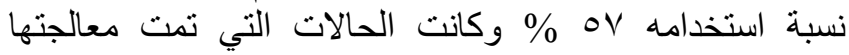

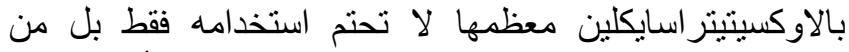
الممكن استخدام مضادات اخرى ولكن تم استخدامه لأنه يفي في في لأني
الجدول ؟: معظم الامراض الجرثومية في الابقار، الأغنامالماعز والدواجن الواردة الى المستشفى البيطري التعليمي في في الإني محافظة كركوك ولاعن

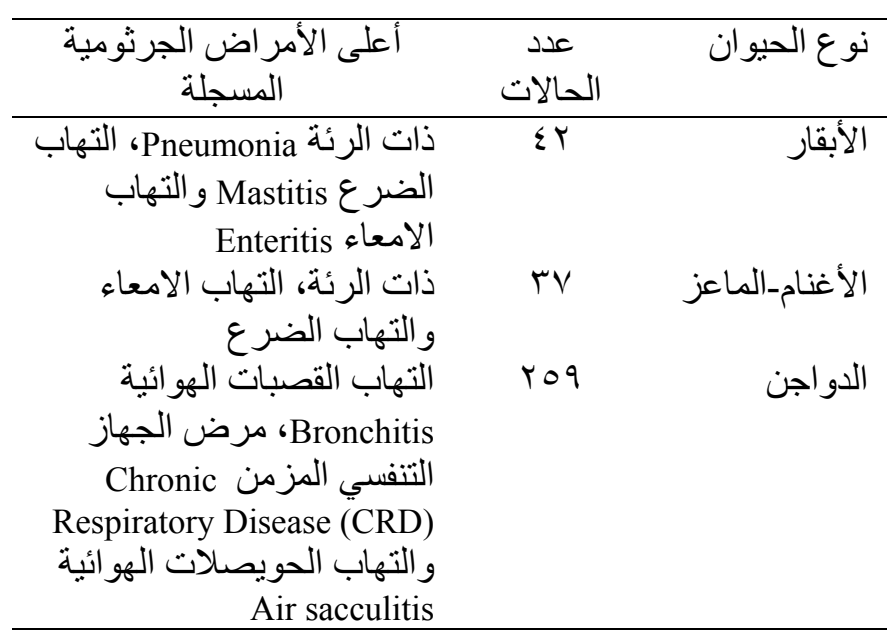

المناقثة

اوضحت هذه الدراسة جوانب عديدة منها النسب المئوية

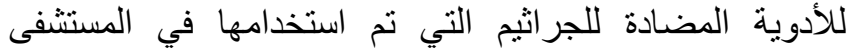

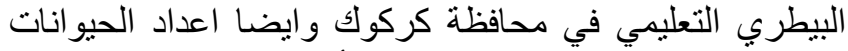

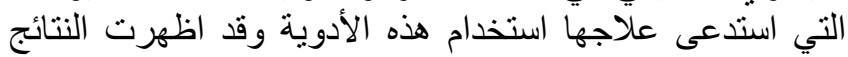

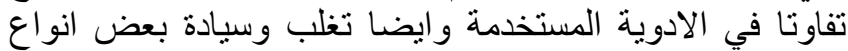

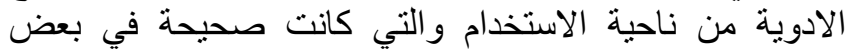

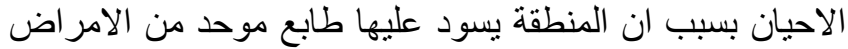

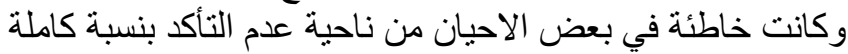

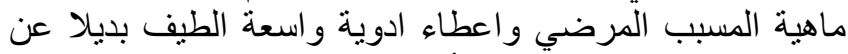

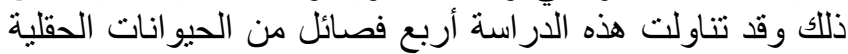

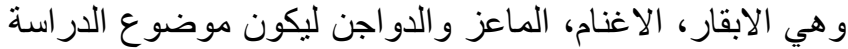

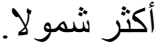
وقد اظهرت النتائج التي تم الحصول عليها اثناء مدة البحث

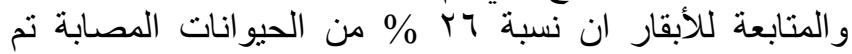
اعطاؤها الاوكسيتتر اسايكلين سو اء في مدة الصيف اون في في الثناء، 


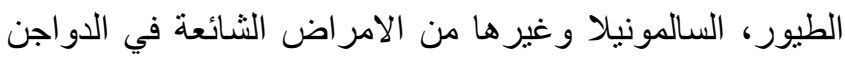

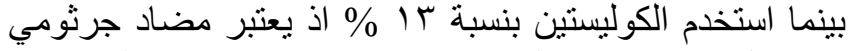

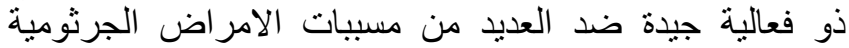

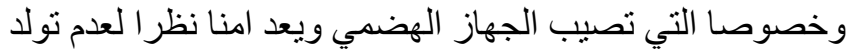
مقاومة تذكر ضدة من قبل الجر اثثم.

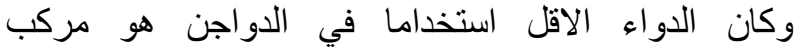

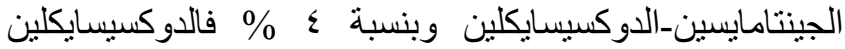

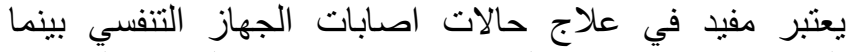

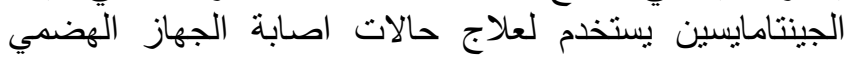
( $\left(11_{6} 1961 \cdot\right)$ تشير نتائج هذه الدراسة المسحية للمستشفى البيطري التعليمي

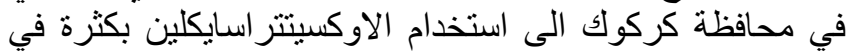
الحيوانات المختلفة وتبعا لتجارب عملية ولئية وعلية بحتية سابقة

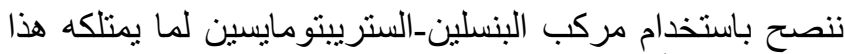

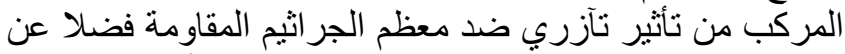

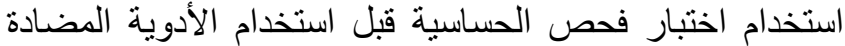

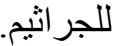

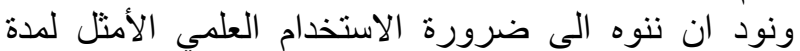

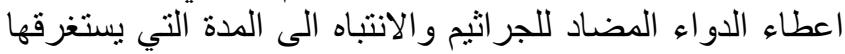

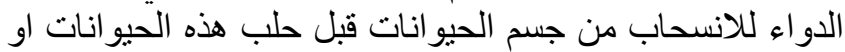
ذبحها لكي لا تتطور المقاومة الجرثومية ضد هذئ هذه الأدوية مستقبلا.

\section{الشكر و التقدير}

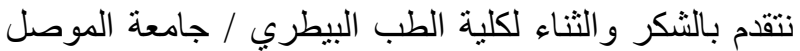

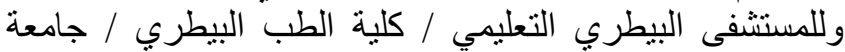

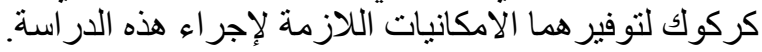

المصادر

1. Maxwell FM. Adventure with antibacterial drugs. Am Soc Clin Pharmacol Therap. 1972;13(4):469-511.

2. Deck DH, Winston LG. Chemotherapeutic drugs. In: Katzung BK, Masters SR and Trevor AJ (eds), Basic and clinical pharmacology. Mc-Grew Hill Philadelphia, USA. 2012;787-790.

3. McEwen SA, Fedorka-Cary PJ. Antimicrobial use and resistance in animal. Clin Infec Dis Oxf J. 2002;34(3):93-106.

4. Sarmah AK, Meyer MT, Boxall AB. A global perspective on the use, sales, exposure pathways, occurrence, fate and effects of veterinary antibiotics. Environ Chemosphere J. 2006;65(5):725-759.

5. WHO. Manual for the laboratory identification and antimicrobial susceptibility testing of bacterial pathogens of public health importance in the Developing World. 2003.

6. Calvin MK. Clinical pharmacology of the new penicillin: II. Effect of drugs which interfere with binding to serum proteins. Clin pharmacol Therap. 1966;7(2): 180-188.

7. Roberts CE, John DA, William MM. Laboratory and clinical studies of penicillin x-1497. Am Soc Clin Pharmacol Therap. 1962;2(1):7079.

8. Harry FD. The newer penicillin. Am Soc Clin Pharmacol Therap. 2013;2(5):572-580.
بعض الاحيان بالغرض في معالجة الحالات المشكوك فيها و التي التي

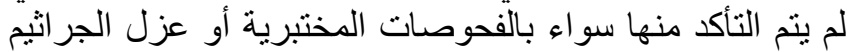

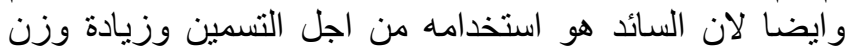

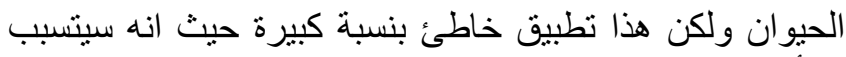

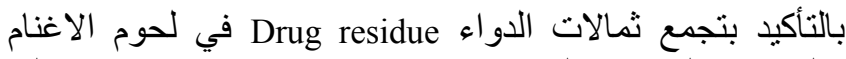

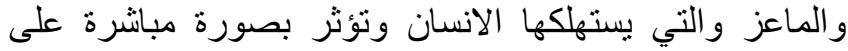

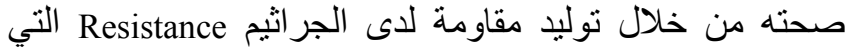

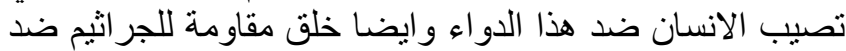

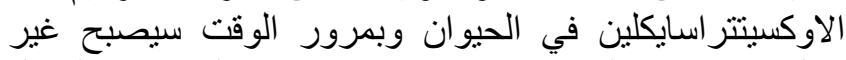
فعال في علاج الجراثيم ويستوجب فئرئ تطوير جيل جديد بالمقابل (1) (1) 11$)$

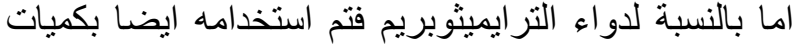

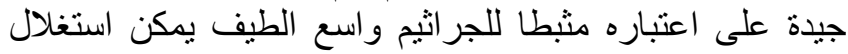

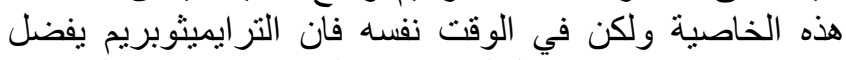

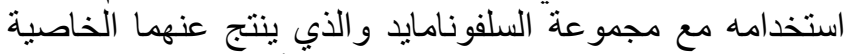
التآزرية التي تزيد من فاعليتهما وتجعل نتأثير هما قاتل للجر اثنيم

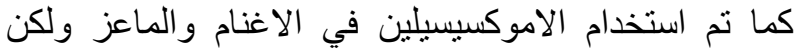

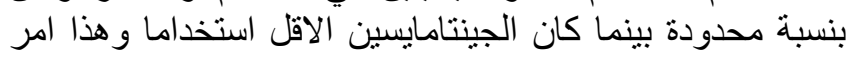

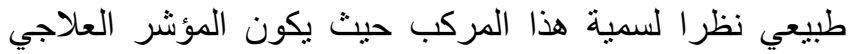
Therapeutic index

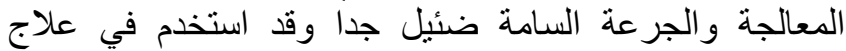

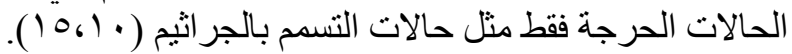

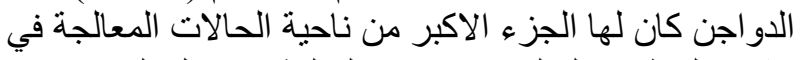

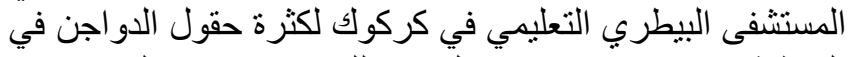

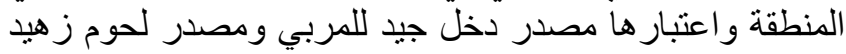

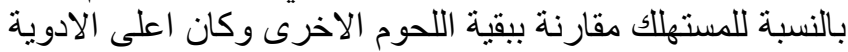

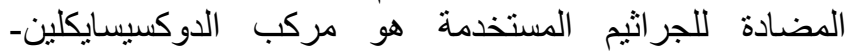

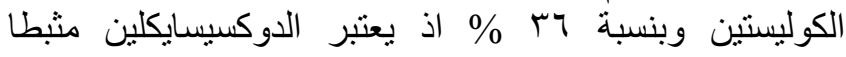

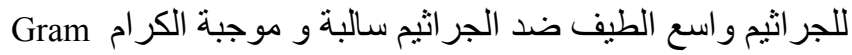
positive

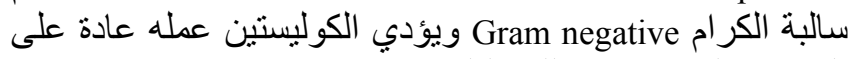

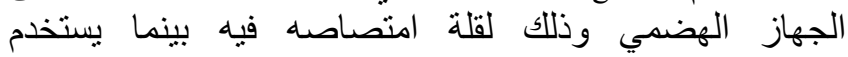

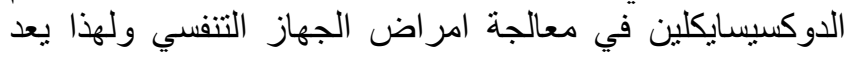

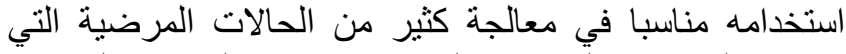

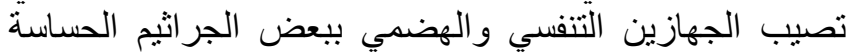

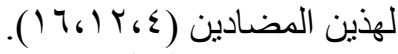

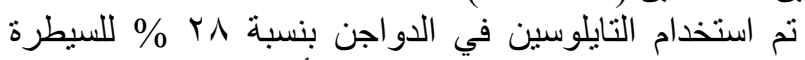

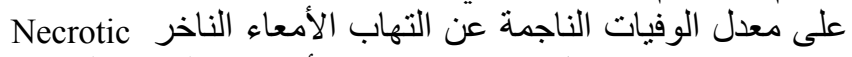
enteritis

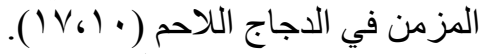

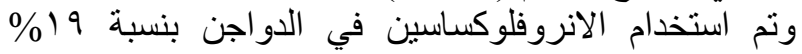

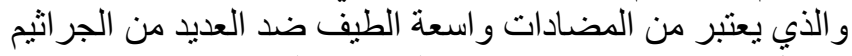

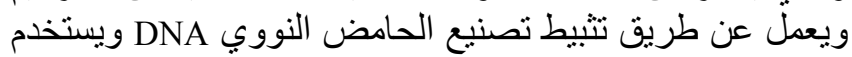
في علاج العديد من الحالات المرضية مثل الرشح، تيفونئ الريد 
14. Dale GF. Penicillin therapy-newer semisynthetic penicillin. Clin Pharmacol Therap. 1965;7(5):706-712.

15. Murry BE. The life and time of the enterococcus. Clin Microbiol Rev J. 1990;3(1):46-56.

16. Sabahy B. Sensitivity test. Glob Vet. 2009;14(4):38.

17. Okeke IN, Lamikanra A, Edelman R. Socioeconomic and behavioral factors leading to acquired bacterial resistance to antibiotics in developing countries. Emerg Infect Dis. 1999;5(1):18-27.

18. Calvin MK, Maxwell FM. Clinical pharmacology of the tetracycline antibiotics. Am Soc Clin Pharmacol Therap. 2013;2(1):51-69.

19. Colonel L, Moser RH. Reaction of tetracycline. Clin Pharmacol Therap. 1966;7(1):117-132.
9. Miranda CD, Zemelman R. Bacterial resistance to Oxytetracycline in Chilean salmon farming. Aquacul. 2002;212:31-47.

10. Kisgen J. Principles of antimicrobial therapy. In: Whalen K, Finkel R, Panvelil TA (eds), Lippincott's pharmacology. Wolters Kluwer Philadelphia, USA. 2015;471-488.

11. Thomas RG, Wilsmore AJ, Simon AJ, Izzard KA. The use of longacting Oxytetracycline for the treatment of ovine foot rot. Brit Vet J. 1994;150(6):561-568.

12. Unger NR, Ganthier TP. Protein synthesis inhibitors. In: Whalen K, Finkel R and Panvelil TA (eds). Lippincott's pharmacology. Wolters Kluwer Philadelphia, USA. 2015;499-513.

13. Colonel L, Moser RH. Disease of medical progress. Clin Pharmacol Therap. 1965;6(3):393-398. 